\title{
Bioethics and Organ Transplantation in a Muslim Society: A Study in Culture, Ethnography, and Religion
}

Author: Farhat Moazam, MD. Publisher: Indiana University Press, 2006. ISBN-10: 0253347823; ISBN-13: 9780253347824.

I t is my pleasure to have received and read Dr. Farhat Moazam's most recent book on organ transplantation. Dr. Moazam and I were classmates at Dow Medical College from 1962-1967. In fact, we were in the same human anatomy dissection group. This is the period of my life that I cited in my paper "the book (human body), which lead to my Creator". After graduation from Karachi University, we went our own directions to different parts of the United States. Dr. Moazam became a pediatric surgeon, and I became an endocrinologist; nonetheless, we had a common passion for medical ethics. I met her most recently in Cairo, Egypt, in 2006, at the international conference of the Islamic Organization for Medical Sciences-Eastern Mediterranean Regional Office (IOMS-EMRO) on ART.

This is a well written book on the development of renal transplantation at Sind Institute of Urology and Transplantation (SIUT) in Karachi, Pakistan, and the ethical concerns related to organ transplantation. It is a very useful book for those interested in Pakistani culture and medical institutions. Having been away from the Pakistani medical field for 38 years, I have learned a lot myself from this book. The author has wisely avoided speaking for Islam and the Islamic world; however, this book can be used as a basis for similar research and survey in other parts of Muslim countries. It is also useful for American ethicists when dealing with Pakistani and Muslim patients in this country.

The book is divided into several sections including her own transformation from a surgeon to an ethicist, development of bioethics in Pakistan, and stories of the lives of transplant patients and their caregivers. Sind Institute of Urology and Transplantation does nearly 100 kidney transplants a year and is famous in this part of the region.

There are many concerns about transplantation including the rights of the donors as well as those of the recipients of the transplantation, the guidelines for transplantation, the availability of organs, and the collection criteria and follow-up after transplantation.

Some of the questions that have been addressed are how Western values are to be incorporated into a third-world country, what are the goals in the development of ethics committees and quality control in transplantation institutions and as far as Muslim countries are concerned, and what are the rights and obligations toward non-Muslim minorities? In Pakistan, the population is $92 \%$ Muslim and $8 \%$ nonMuslim. Are the non-Muslim Christians and Hindus treated the same way as Muslims are, or do Islamic culture and ethics apply to them as well? Who safeguards the interests of non-Muslims? Is it the state, the judiciary, or their caregiver? There is a good discussion on many of the controversial areas in the book with plenty of references and citations to additional reading. It is a book worth keeping, not only in hospitals, institutions and libraries, but also on the shelves of ethicists and caregivers involved in transplantation, not only in Pakistan but elsewhere.

\section{Submitted by}

Shahid Athar, MD

Endocrinologist and

Former Chair, Medical Ethics Committee

Islamic Medical Association of North America 